\title{
Surgical resection does not avoid the risk of diverticulitis recurrence -a systematic review of risk factors
}

\author{
Gregoire Longchamp ${ }^{1}$ (D) Ziad Abbassi $^{1}$ (D) - Jeremy Meyer ${ }^{1}$ (D) $\cdot$ Christian Toso ${ }^{1}$ (D) - Nicolas C. Buchs ${ }^{1}$ (D) \\ Frederic Ris ${ }^{1}$
}

Accepted: 17 September 2020 / Published online: 28 September 2020

(C) The Author(s) 2020

\begin{abstract}
Purpose Fifteen percent of patients undergoing elective sigmoidectomy will present a diverticulitis recurrence, which is associated with significant costs and morbidity. We aimed to systematically review the risk factors associated with recurrence after elective sigmoidectomy.

Methods PubMed/MEDLINE, Embase, Cochrane, and Web of Science were searched for studies published until May 1, 2020. Original studies were included if (i) they included patients undergoing sigmoidectomy for diverticular disease, (ii) they reported postoperative recurrent diverticulitis, and (iii) they analyzed $\geq 1$ variable associated with recurrence. The primary outcome was the risk factors for recurrence of diverticulitis after sigmoidectomy.

Results From the 1463 studies initially screened, six studies were included. From the 1062 patients included, 62 patients recurred $(5.8 \%)$, and six variables were associated with recurrence. Two were preoperative: age $(\mathrm{HR}=0.96, p=0.02)$ and irritable bowel syndrome $(33.3 \%$ with recurrence versus $12.1 \%$ without recurrence, $p=0.02)$. Two were operative factors: uncomplicated recurrent diverticulitis as indication for surgery $(73.3 \%$ with recurrence versus $49.9 \%$ without recurrence, $p=0.049)$ and anastomotic level (colorectal: $\mathrm{HR}=11.4, p=0.02$, or colosigmoid: $\mathrm{OR}=4, p=0.033$ ). Two were postoperative variables: the absence of active diverticulitis on pathology (39.6\% with recurrence versus $26.6 \%$ without recurrence) and persistence of postoperative pain $(\mathrm{HR}=4.8, p<0.01)$.

Conclusion Identification of preoperative variables that predict the occurrence of diverticulitis recurrence should help surgical decision-making for elective sigmoidectomy, while peri- and postoperative factors should be taken into account for optimal patient follow-up.
\end{abstract}

Keywords Diverticulitis $\cdot$ Sigmoidectomy $\cdot$ Postoperative recurrence $\cdot$ Risk factors

\section{Introduction}

Diverticulosis is defined by the presence of colonic diverticula which are protrusions of the mucosa and submucosa through the colonic wall. More than $90 \%$ of colonic diverticula are found in the left colon and sigmoid [1]. Based on an American population aged between 30 and 80 years

Electronic supplementary material The online version of this article (https://doi.org/10.1007/s00384-020-03762-0) contains supplementary material, which is available to authorized users.

Frederic Ris

frederic.ris@hcuge.ch

1 Division of Digestive Surgery, University Hospitals of Geneva, Rue Gabrielle-PerreT-Gentil 4, 1211 Geneva, Switzerland undergoing outpatient colonoscopies, diverticulosis was present in $42 \%$ of patients [2]. This prevalence was increased in elderly, white population, overweight, smokers, and patients with decreased bowel movements [2]. Patients may remain asymptomatic, whereas others will develop diverticular disease, defined as symptomatic diverticulosis. Therefore 10 $25 \%$ of patients with diverticulosis will manifest diverticular inflammation, and $12 \%$ of patients with diverticulitis will developed a complication such as abscess, perforation, fistula, stricture or obstruction [3].

The Hinchey classification modified by Wasvary et al. [4] is often used to classify severity of episode of diverticulitis. That classification includes four stages: stage Ia corresponds to a confined inflammation or phlegmon; stage Ib is characterized by a pericolic or mesenteric abscess; stage II is characterized by a distant abscess in the abdomen, pelvis, or 
retroperitoneum; and perforation leading to purulent or fecal peritonitis correspond to stages III or IV, respectively.

The European Association for Endoscopic Surgery (EAES) and other interventional techniques and Society of American Gastrointestinal and Endoscopic Surgeons (SAGES) published guidelines in 2019 [5] recommending emergent sigmoid resection for Hinchey III and IV diverticulitis or after failure of conservative therapies for earlier stages. Elective sigmoidectomy was recommended in the case of decreased quality of life caused by diverticular disease. Moreover, chronic symptoms or smoldering disease, severity of prior episodes, comorbidities, and patient preferences should be taken into consideration [6].

Nevertheless, sigmoidectomy, although removing the segment of the colon the most affected by diverticula, as well as the recto-sigmoid junction, does not remove diverticula from the remaining colon. After a mean follow-up of 10 years, a recurrence rate of $15 \%$ after elective surgery for diverticulitis was reported [7]. Mechanism for these recurrences is not clear. However, several risk factors were identified. Prediction of these recurrences is important to prevent associated costs and morbidity [8]. Therefore, we aimed to systematically review the risk factors associated with recurrence of diverticulitis after elective sigmoidectomy.

\section{Materials and methods}

This systematic review was performed in accordance with the recommendations of the Preferred Reporting Items for Systematic Review and Meta-analyses (PRISMA) statement [9] (Supplementary Table 1).

\section{Data source and search strategy}

Two reviewers (GL, ZA) independently searched PubMed/ MEDLINE, Embase, Cochrane, and Web of Science for studies published until May 1, 2020, without limitation based on the publication year. The following search terms were used: "diverticulitis" OR "diverticulum" AND "inflammation", AND "surgery" OR "colectomy", AND "recurrence" in MeSH terms; and "diverticula" OR "diverticulosis", AND "resection" OR "sigmoidectomy" OR "Hartmann*", AND "recurrent" OR "failure" in non-MeSH terms. Additionally, a manual cross-reference search of bibliographies of relevant articles was performed to identify additional studies.

\section{Study selection}

Original studies written in English were eligible for inclusion if they fulfilled all the following criteria: (i) they included patients undergoing elective sigmoidectomy for diverticular disease, (ii) they reported postoperative recurrent diverticulitis, and (iii) they reported $\geq 1$ variable associated with recurrence. Studies were excluded if postoperative recurrence was not confirmed by imaging or if the definition of recurrence was not specified. Studies including surgical procedure without resection (i.e., peritoneal lavage, surgical drainage) were excluded. Other exclusion criteria were case reports, conference abstracts, editorials, and protocols. There was no restriction based on the design or sample size of the study.

\section{Data extraction}

Two authors (GL, ZA) independently extracted the data, including general and methodological information of the study and baseline characteristics of the study population: sample size, age, gender, classification of diverticulitis, the number of previous episodes of diverticulitis, and indication for surgery. Intraoperative data were also extracted, including elective/ emergency intervention, type of resection (sigmoidectomy/ left-sided hemicolectomy/anterior resection), splenic flexure mobilization, laparoscopic/open resection, conversion, creation of ostomy, and type of anastomosis (stapled/handsewn, colorectal/colosigmoid). Postoperative extracted data were follow-up duration, pathology report (specimen length, inflammation state [active, chronic, none]), persistent complaints, complications, recurrence, and treatment for recurrence. Variables associated with recurrence on quantitative analysis and variables significant on uni- or multivariate regression analysis were also extracted.

\section{Outcome measures}

The primary outcome of the systematic review was to identify risk factors for postoperative recurrence of diverticulitis. The secondary outcomes were the incidence of postoperative recurrence of diverticulitis, treatment for postoperative recurrence of diverticulitis (medical versus surgical), postoperative complications, and mortality.

Recurrence was defined as left lower quadrant pain, inflammation (fever, elevated white blood cell, or C-reactive protein), and imaging consistent with the diagnosis of diverticulitis. Complication was defined as any deviation from the normal postoperative course and did not include recurrence.

\section{Results}

\section{Studies selection and characteristics}

The initial search identified 1463 studies (Fig. 1). After duplicates removal, 1186 records were screened. Based on the title and abstract, 963 studies were removed. From the 223 full text articles assessed for eligibility, 208 were excluded because they did not fulfill all inclusion criteria. Furthermore, nine other 
Fig. 1 Preferred Reporting Items for Systematic Review and Metaanalyses (PRISMA) flowchart showing selection of publications for review

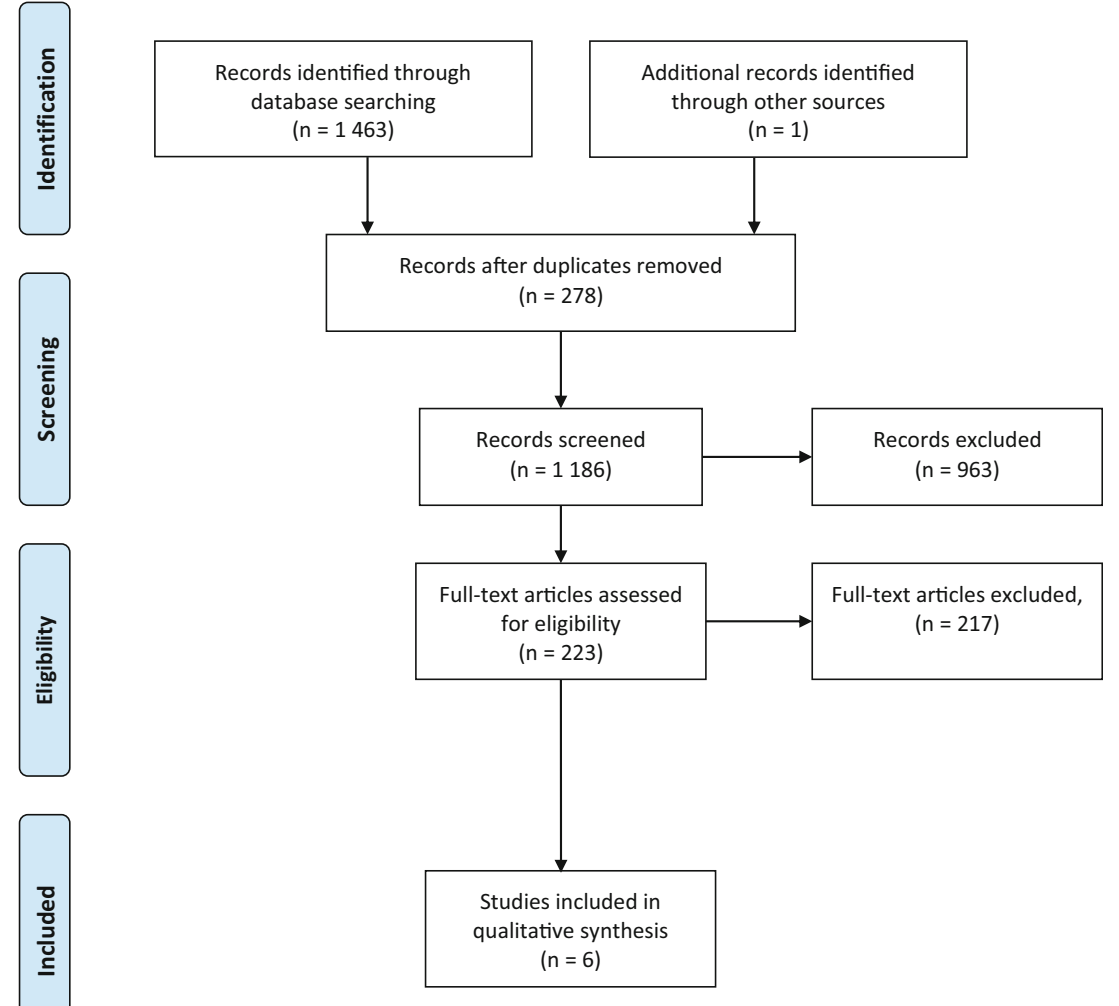

studies were removed: one study [10] contained duplicated data from another included study; two studies [11, 12] included peritoneal lavage, surgical drainage, or diverticulectomy in the resection group; in five studies [13-17] recurrences were not defined or confirmed by imaging; and one study [18] contained insufficient data. One study [19] was identified by cross-referencing. Finally, six articles [19-24] were included in the present review.

From the included studies, five studies were monocentric [19-23] and retrospective observational cohort [19-22, 24] (Table 1). Overall, 1062 patients were included (518 males and 544 females) with a mean age ranging from 56 to 63 years. Data regarding the mean follow-up duration was reported by 4 studies [19-21, 24], which ranged from 55 to 86 months. Before the surgical procedure, 765 (72\%) patients experienced recurrent attacks of diverticulitis, and 128 (12\%) presented their first episode (data unavailable for 169 (16\%) of cases). Only two studies $[22,23]$ reported the severity of the diverticulitis episode, classified either with the Hinchey classification [25] or with the Hansen and Stock classification [26].

\section{Perioperative and postoperative outcomes}

Only one study [20] included emergency surgical resections, representing $73(7 \%)$ of patients included in the review (Table 2). The remaining patients represented 953 (93\%) cases, which underwent elective intervention for uncomplicated diverticulitis [19-21,24] or complicated diverticulitis [20-22]. Other reported indications for surgery were symptomatic diverticulosis [23], persistent abdominal pain/smoldering disease [21, 22], recurrent bleeding [22], failure of conservative treatment for diverticulitis [22], and first attack of diverticulitis in immunosuppressed patients [22]. Sigmoidectomy was the procedure of choice in $928(90 \%)$ patients, while anterior resection or left-sided hemicolectomy were not routinely performed (11 patients and 38 patients, respectively; type of intervention performed not reported for 85 patients). Details of the operative techniques are detailed in Table 2.

Pathology showed a mean specimen length from 14 to $26 \mathrm{~cm} \mathrm{[19-24]} \mathrm{and} \mathrm{the} \mathrm{presence} \mathrm{of} \mathrm{diverticulitis} \mathrm{in} 536$ cases, but no inflammation in 177 cases [19-21, 23] (Table 3). Moreover, inflammation at the proximal margin was reported by two studies in 13 [19] and 30 [24] patients. Data on the presence of postoperative persistent complaints was reported by one study [20] in 36 patients. Five studies [19-22, 24] reported postoperative complications, corresponding to a total of 136 events and an incidence of 14.0\% (136/968); and four studies $[19,20,22,24]$ reported postoperative death, corresponding to 8 patients and a mortality of $1.3 \%(8 / 607)$.

\section{Postoperative recurrence of diverticulitis}

A total of 62 diverticulitis recurred after surgical resection for diverticular disease, representing $5.8 \%$ of the population 


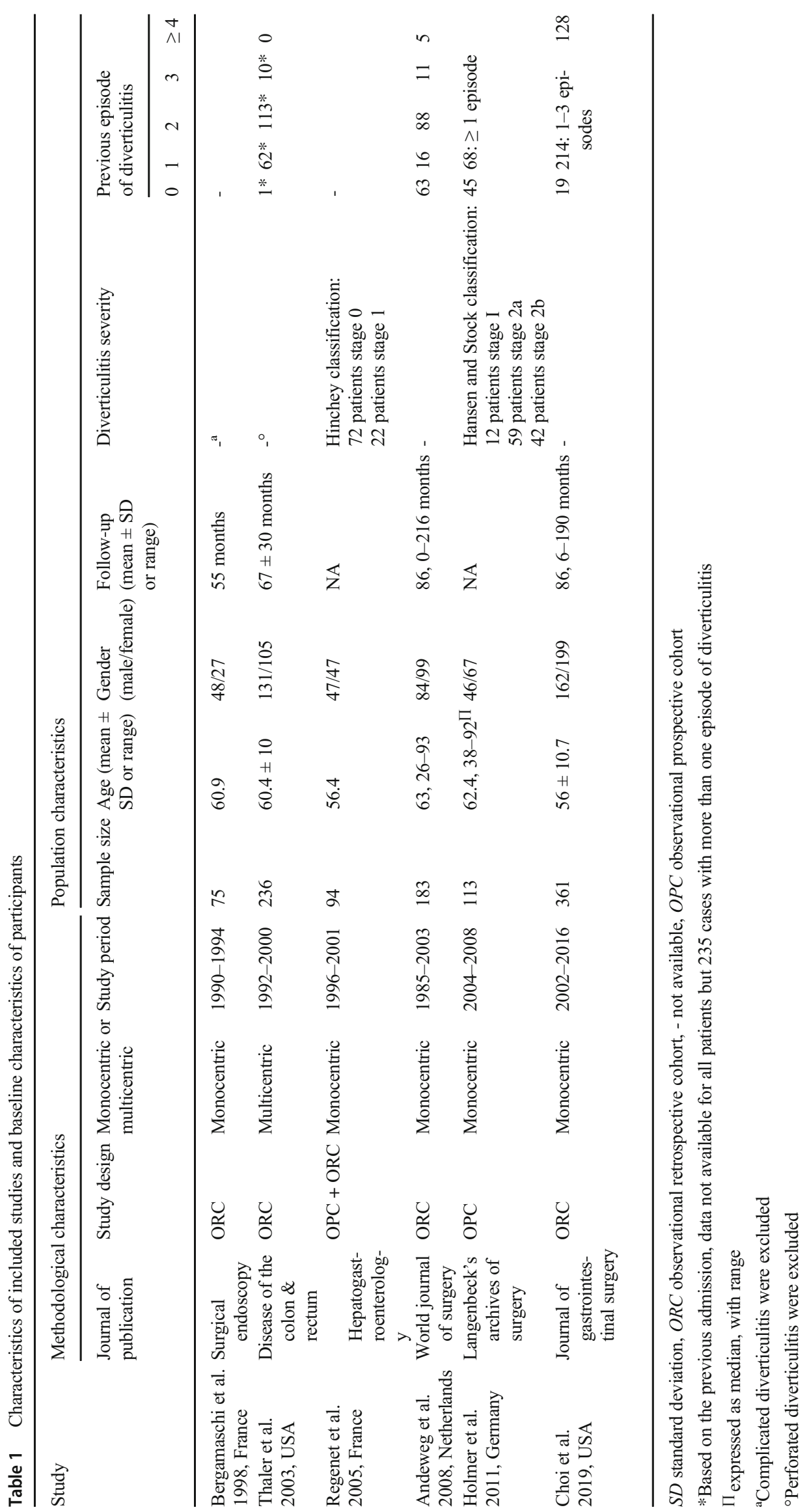




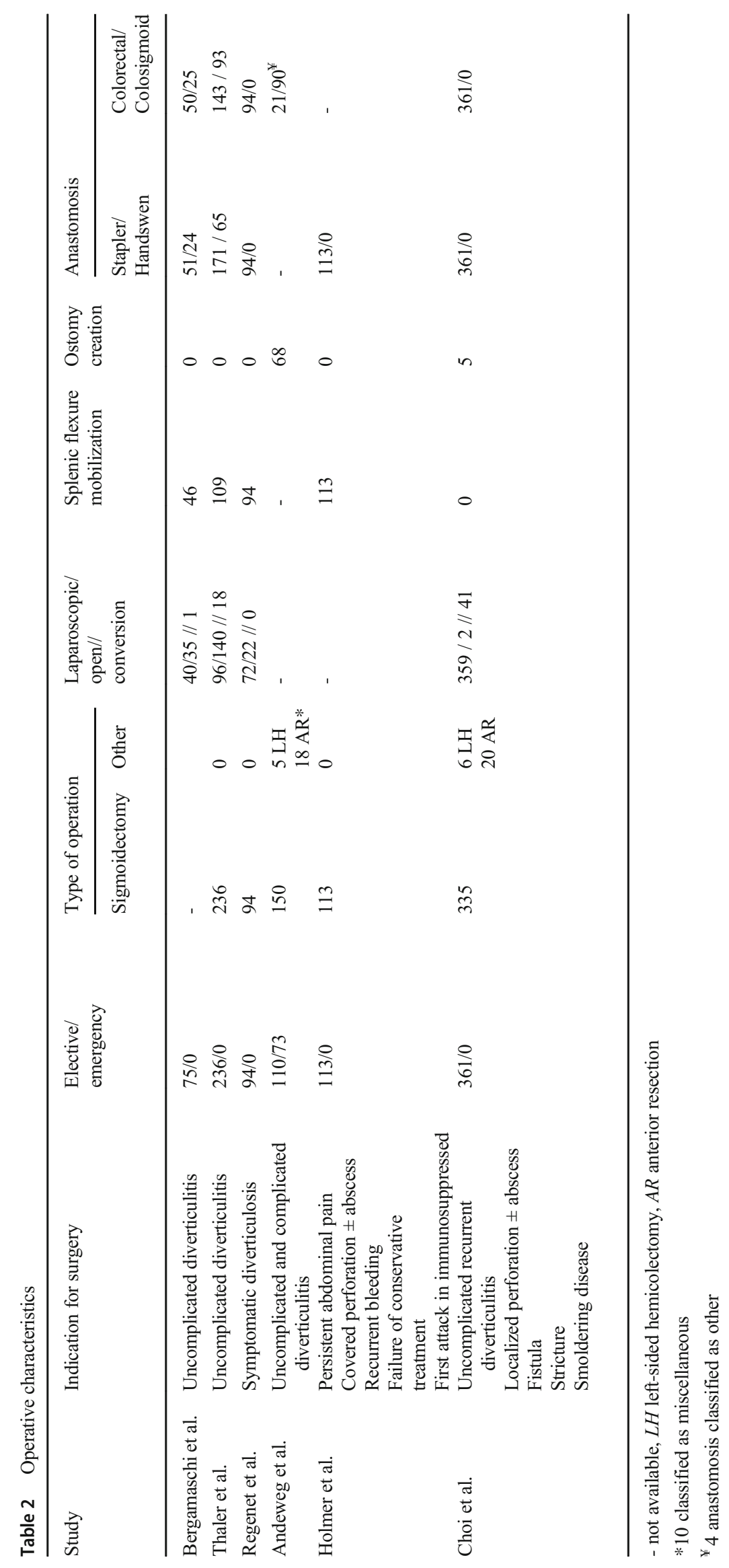


Table 3 Postoperative outcomes

\begin{tabular}{|c|c|c|c|c|c|}
\hline \multirow[t]{2}{*}{ Study } & \multicolumn{2}{|l|}{ Pathology } & \multirow[t]{2}{*}{ Complications (timepoint) } & \multirow[t]{2}{*}{ Persistent complains } & \multirow[t]{2}{*}{ Mortality (timepoint) } \\
\hline & $\begin{array}{l}\text { Specimen length } \\
(\text { mean } \pm \text { SD or range })\end{array}$ & Pathologist assessment & & & \\
\hline Bergamaschi et al. & $14.3 \mathrm{~cm}$ & 75 diverticulitis ${ }^{\Pi}$ & 8 & - & 0 \\
\hline Thaler et al. & $17.9 \pm 5.9 \mathrm{~cm}$ & $-\Pi$ & 54 (30 days) & - & 1 (30 days) \\
\hline Regenet et al. & $26.3 \mathrm{~cm}$ & 94 diverticulitis & - & - & - \\
\hline Andeweg et al. & $17.3,7-35 \mathrm{~cm}$ & $\begin{array}{l}166 \text { acute diverticulitis } \\
17 \text { no inflammation }\end{array}$ & $9 *$ & 36 & 7 \\
\hline Holmer et al. & - & - & 16 & - & 0 \\
\hline Choi et al. & $17.7 \mathrm{~cm}$ & $\begin{array}{l}141 \text { acute diverticulitis } \\
60 \text { chronic diverticulitis } \\
158 \text { diverticular disease } \\
2 \text { no disease }\end{array}$ & 49 (perioperative) & - & - \\
\hline
\end{tabular}

$S D$ standard deviation, $\mathrm{cm}$ centimeter, - not available

$\Pi$ inflammation at the proximal margin was reported in 13 cases by Bergamaschi et al. and in 30 cases by Thaler et al.

*only severe complications were reported

included in the review. Mean time to recurrence ranged between 38 [20] and 78 months [24], and the cumulative time-related incidence at 15 years ranged between 6.3 [21] and16\% [20] (Table 4). The treatment for postoperative recurrence was conservative in 43 patients, but 14 patients required another surgical intervention (treatment not reported by one study [23]).

\section{Preoperative variables associated with postoperative recurrence of diverticulitis}

Eight preoperative variables were considered for their association with recurrence of postoperative diverticulitis (Table 5). Age was not associated with postoperative recurrence in the retrospective study by Choi et al. [21] $(p=0.12)$. However,
Andeweg et al. [20] reported a lower age to be associated with recurrence (mean 54, range 33-75, versus without recurrence: mean 64 , range $27-93, p<0.02$ ). On regression analysis (Cox-model), younger age was still an independent predictor of recurrence (univariate: hazard ratio $(\mathrm{HR})=0.96,95 \% \mathrm{CI}$ 0.93-0.99, $p=0.02$; multivariate: stated as significant but no value reported). Irritable bowel syndrome was the other preoperative variable associated with recurrence on univariate analysis $(33.3 \%$ with recurrence versus $12.1 \%$ without recurrence, $p=0.02$ ) [21]. Nevertheless, the latter was not significant on regression analysis $(p=0.053)$. Six preoperative variables showed no significant association with recurrence: the number of preoperative episodes of diverticulitis (reported by four studies [20-22, 24]), gender (reported by three studies

Table 4 Reported recurrences of included studies

\begin{tabular}{|c|c|c|c|c|c|}
\hline \multirow[t]{2}{*}{ Study } & \multirow[t]{2}{*}{$\begin{array}{l}\text { Number of recurrence } \\
(\%)\end{array}$} & \multirow[t]{2}{*}{$\begin{array}{l}\text { Time until recurrence } \\
\text { (mean } \pm \mathrm{SD} \text { or range) }\end{array}$} & \multirow[t]{2}{*}{ Cumulative time-related incidence of recurrence } & \multicolumn{2}{|c|}{$\begin{array}{l}\text { Treatment for recurrent } \\
\text { diverticulitis }\end{array}$} \\
\hline & & & & Conservative & Surgical \\
\hline Bergamaschi et al. & $4(5.3 \%)$ & - & - & 4 & 0 \\
\hline Thaler et al. & $12(5.1 \%)$ & $78 \pm 25$ months & - & 11 & 1 \\
\hline Regenet et al. & $5(5.3 \%)$ & - & - & - & \\
\hline Andeweg et al. & $16(8.7 \%)$ & $38,6-144$ months & $\begin{array}{l}1 \text { year: } 3 \% \text { (SE } 1.3) 5 \text { years: } 8.2 \% \text { (SE } 2.3 \text { ) } \\
10 \text { years: } 12 \% \text { (SE } 3.0) 15 \text { years: } 16 \%(\text { SE } 3.7)\end{array}$ & 8 & $8^{\Pi}$ \\
\hline Holmer et al. & $4(3.5 \%)$ & - & - & 4 & 0 \\
\hline Choi et al. & $21(5.8 \%)$ & $55,6-109$ months & 1 year: $0.3 \% 5$ years: $3.0 \% 10$ years: $6.3 \% 15$ years: $6.3 \%$ & 16 & $5^{*}$ \\
\hline Overall & $62(5.8 \%)$ & - & - & 43 & 14 \\
\hline
\end{tabular}

$S D$ standard deviation, - not available, $S E$ standard error

$\Pi_{3}$ left hemicolectomy, 3 partial resection of transverse colon, 2 subtotal colectomy

*5 left colectomies 
Table 5 Preoperative variables associated with postoperative recurrence of diverticulitis

\begin{tabular}{|c|c|c|c|}
\hline Study & Univariate analysis & Univariate regression analysis & Multivariate regression analysis \\
\hline \multicolumn{4}{|c|}{ Number of preoperative episodes of diverticulitis } \\
\hline Thaler et al. & - & NS & - \\
\hline Andeweg et al. & NS & NS & - \\
\hline Choi et al. & NS & - & - \\
\hline Holmer et al. & NS & - & - \\
\hline \multicolumn{4}{|l|}{ Gender } \\
\hline Thaler et al. & - & NS & - \\
\hline Andeweg et al. & NS & - & - \\
\hline Choi et al. & NS & - & - \\
\hline \multicolumn{4}{|c|}{ Age: mean, range with recurrence versus without recurrence } \\
\hline Andeweg et al. & $54,33-75$ versus $64,27-93, p<0.02$ & HR $0.96,95 \%$ CI $0.93-0.99, p=0.02$ & Significant (value NA) \\
\hline $\begin{array}{l}\text { Choi et al. } \\
\text { ASA class }\end{array}$ & NS & - & - \\
\hline $\begin{array}{l}\text { Thaler et al. } \\
\text { Comorbidity }\end{array}$ & \multicolumn{2}{|c|}{ Comorbidity } & - \\
\hline Choi et al. & NS & - & - \\
\hline \multicolumn{4}{|c|}{ Irritable bowel syndrome: $n(\%)$ with recurrence versus without recurrence } \\
\hline Choi et al. & $5(33.3 \%)$ versus $42(12.1 \%), p=0.02$ & NS & - \\
\hline \multicolumn{4}{|c|}{ Previous treatment modality: antibiotic IV versus antibiotic $\mathrm{PO}$ versus drainage } \\
\hline Choi et al. & NS & - & - \\
\hline \multicolumn{4}{|c|}{ Previous abdominal surgery } \\
\hline Thaler et al. & - & NS & - \\
\hline
\end{tabular}

$N S$ not significant, $A S A$ American Society of Anesthesiologists, $I V$ intravenous, $P O$ per os, - not available

$[20,21,24])$, American society of anesthesiologists (ASA) class and previous abdominal surgery (both reported by one study [24]), comorbidity, and previous treatment modality (both reported by one study [21]).

\section{Operative variables associated with postoperative recurrence of diverticulitis}

From the eight operative variables, only two $[20,21,24]$ were associated with recurrence (Table 6). The first variable was uncomplicated recurrent diverticulitis as indication for surgery (73.3\% with recurrence versus $49.9 \%$ without recurrence, $p=$ 0.049 ), but the association was not significant on univariate regression analysis [21]. Anastomotic level was considered by three studies [20,23,24], but significant in two studies $[20,24]$ on univariate regression analysis. Andeweg et al. [20] reported increased recurrences associated with colorectal anastomosis compared with colostomy (univariate regression analysis: $\mathrm{HR}=11.4,95 \%$ CI 1.2-109.5, $p=0.02$; multivariate regression analysis: stated as significant but no value reported). In the other hand, Thaler et al. [24] reported colosigmoid anastomosis as a risk factor for postoperative recurrent diverticulitis (univariate regression analysis: odds ratio $(\mathrm{OR})=4$, 95\% CI 1.1-15.0, $p=0.033$; no multivariate regression analysis). Six other factors were not associated with postoperative recurrence of diverticulitis: emergency/elective surgery [20], laparoscopic/ open approach [19, 23, 24], length of resected bowel [20, 21, $23]$, type of resection [20,21], splenic flexure mobilization [24], stapled/handsewn anastomosis [24].

\section{Postoperative variables associated with postoperative recurrence of diverticulitis}

Four postoperative variables were included in the analysis for their association with diverticulitis (Table 7). The absence of active diverticulitis on pathology was significant on univariate analysis only in the study by Choi et al. [21] (39.6\% with recurrence versus $26.6 \%$ without recurrence, $p=0.01$ ). However, two studies [20, 24] reported no association between the pathology and the recurrence of postoperative diverticulitis. Persistence of postoperative pain was associated with recurrence on univariate analysis but also on uni- and multivariate regression analysis $(22 \%$ with recurrence versus $5.4 \%$ without recurrence, $p<0.01$; HR $=4.8,95 \%$ CI 1.8 $12.5, p<0.01$; stated as significant but no value reported; respectively) [20]. Two postoperative factors were not associated with recurrence, as reported by one study [24]: postoperative complications and reoperation. 


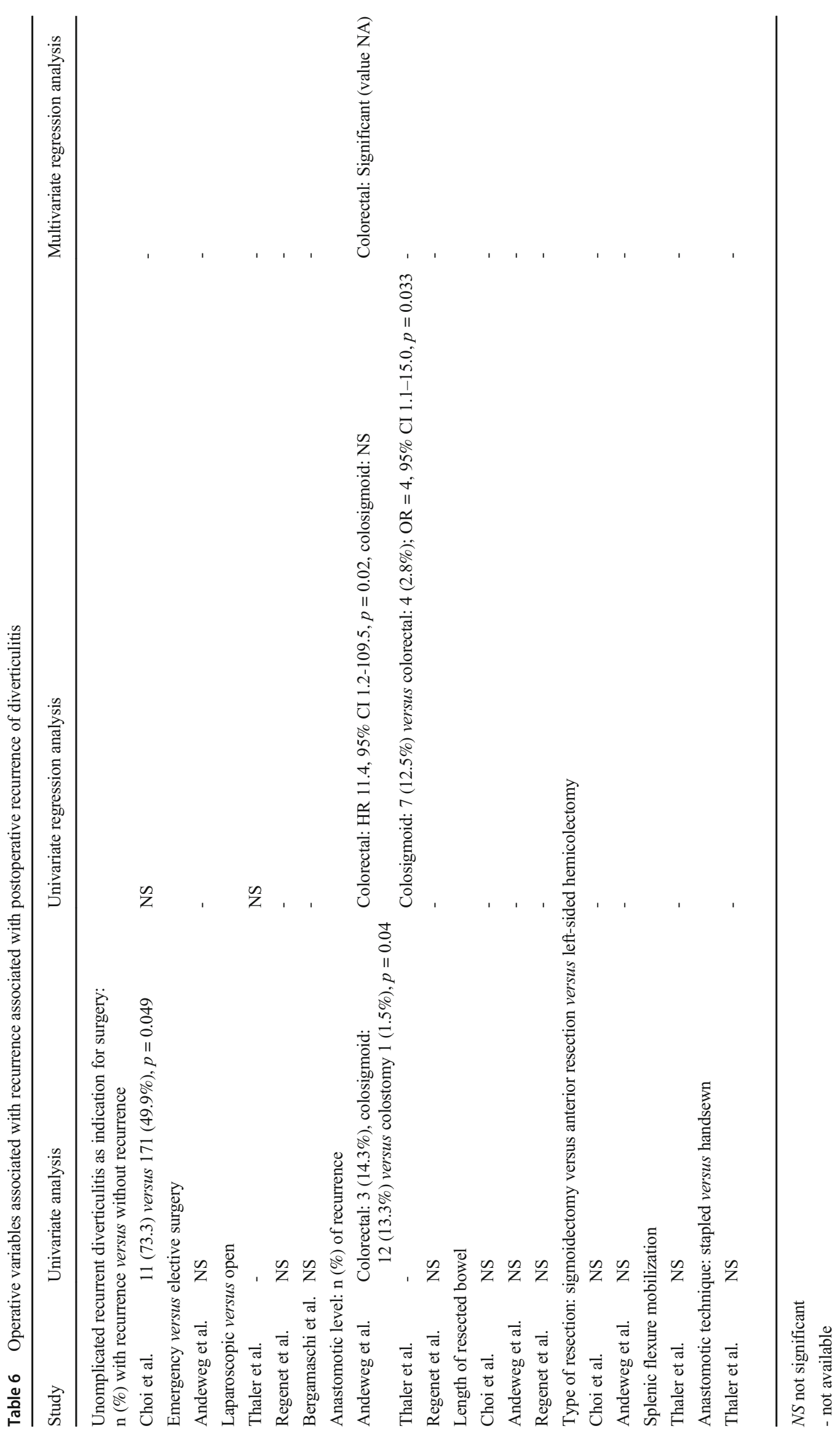


Table 7 Postoperative variables associated with recurrence associated with postoperative recurrence of diverticulitis

\begin{tabular}{|c|c|c|c|}
\hline Study & Univariate analysis & Univariate regression analysis & Multivariate regression analysis \\
\hline \multicolumn{4}{|c|}{ Acute diverticulitis on pathology: $n(\%)$ with recurrence versus without recurrence } \\
\hline Choi et al. & $4(26.6 \%)$ versus $137(39.6 \%), p=0.01$ & NS & - \\
\hline Andeweg et al. & NS & - & - \\
\hline Thaler et al. & - & $\mathrm{NS}^{\Pi}$ & - \\
\hline \multicolumn{4}{|c|}{$\begin{array}{l}\text { Persistent postoperative pain: } \mathrm{n}(\%) \text { of recurrences in patients with } \\
\text { persistent pain versus } \mathrm{n}(\%) \text { of recurrences without persistent pain }\end{array}$} \\
\hline Andeweg et al. & $8(22.2 \%)$ versus $8(5.4 \%), p<0.01$ & HR $4.8,95 \%$ CI $1.8-12.5, p<0.01$ & Significant (value NA) \\
\hline \multicolumn{4}{|c|}{ Postoperative complication } \\
\hline Thaler et al. & - & NS & - \\
\hline \multicolumn{4}{|l|}{ Reoperation } \\
\hline Thaler et al. & - & NS & - \\
\hline
\end{tabular}

\section{Discussion}

The present systematic review included six observational cohorts [19-24], totalizing 1062 patients with diverticular disease. Recurrence occurred in 62 cases and needed conservative (43 cases) or surgical (14 cases) treatment. Three variables were significantly associated with postoperative recurrence of diverticulitis, one for each pre-, peri- or postoperative category. From the eight preoperative variables, a lower age [20] was associated with recurrence. From the eight perioperative factors, the anastomotic level was significant on regression analysis. Three studies [20,21, 24] integrated four postoperative variables, of which persistent postoperative pain [20] was associated with recurrence on Cox regression model.

Our review had several limitations. Firstly, regression analysis was not undertaken by all the included studies. Secondly, risk of bias was high due to the design of the included studies (one prospective [22], four retrospectives [19-21,24], and one mixed [23] observational cohorts). Thirdly, the study populations were small, and only one study [24] was multicentric. Fourthly, data were heterogeneous across studies (i.e. severity staging of the diverticulitis, indication fur surgery, operative technique, and definition of complications). Fifthly, the search strategy may have not retrieved all relevant studies.

Importantly, diverticulosis in limited to the descending colon and sigmoid in $>90 \%$ of cases [1] and sigmoidectomy seemed a good option for the treatment of diverticulitis [5]. However, it might not be a definitive cure for all patients, as showed by a cumulative time-related incidence of postoperative recurrence at 15 years ranging between 6.3 and $16 \%$ [20, 21]. Risk factors for recurrence should be identified, to avoid increased costs and morbidity. A systematic review by Hupfeld et al. [27] identified three factors with high likelihood to increase the risk of diverticulitis recurrence after non-surgical management: young age, diverticulitis complicated by an abscess formation, and recurrent diverticulitis. Compared with the latter review [27], we presently included two studies $[20,21]$ which assessed the relationship between age and postoperative recurrence. While one study [21] failed to find an association, another study [20] showed decreased recurrence in older patients (HR $=0.96,95 \%$ CI $0.93-0.99, p$ $=0.02$ ). This might be explained by the decreased life expectancy while reappearance of diverticulitis could occur.

Herein, we presented the first systematic review of variables associated with postoperative recurrence. Identification of these factors could help optimization of the treatment strategy. From six identified variables, only the anastomotic level is modifiable. Based on a low level of evidence, the EAES and SAGES recommended colorectal anastomosis to decrease the risk of postoperative recurrence. This statement is supported by the study by Thaler et al. [24] reporting increased recurrences with colosigmoid anastomosis versus colorectal anastomosis. However, Andeweg et al. [20] showed increased recurrences with colorectal anastomosis versus colostomy, and Regenet et al. [23] found no association between the anastomotic level and postoperative recurrence. Because the results are conflictual, we could not favor an anastomotic level over another. Moreover, five additional non-modifiable risk factors were identified. Because elective sigmoidectomy is associated with postoperative complication rate of $22.5 \%$ and 30-day mortality rate of $0.5 \%$ [28], benefices should be weight against the risks. This balance should consider postoperative recurrence and associated risk factors, together with the patient preferences and global condition.

Future researches are needed to identify risk factors for postoperative recurrence. Our review reported conflicting 
results, and significant association between variable and recurrence were reported by isolated study. Moreover, future trials should include larger prospective cohorts.

\section{Conclusions}

To conclude, surgeons should be aware of the risk of postoperative diverticulitis recurrence, and patients should be informed. Preoperative variables associated with postoperative recurrence should be considered by clinicians for adequate patient selection and aid surgical decision-making for elective sigmoidectomy. Moreover, peri- and postoperative variables should be emphasized for optimal patient follow-up and early recognition of recurrence to avoid complication and reoperation.

Authors' contribution GL and ZA conceived and designed the study. GL and ZA acquired the data. GL, ZA, JM, CT, NCB, and FR interpreted the data. GL, ZA, JM, CT, NCB, and FR contributed to the writing of the manuscript and to its critical revision. GL, ZA, JM, CT, NCB, and FR approved the final version of the manuscript.

Funding Open access funding provided by University of Geneva.

Availability of data and material The authors confirm that the data supporting the findings of this study are available within the article.

\section{Compliance with ethical standards}

Conflicts of interests The authors have no conflicts of interest to disclose.

Ethics approval Not applicable

Consent to participate Not applicable.

Consent for publication Not applicable.

Code availability Not applicable.

Open Access This article is licensed under a Creative Commons Attribution 4.0 International License, which permits use, sharing, adaptation, distribution and reproduction in any medium or format, as long as you give appropriate credit to the original author(s) and the source, provide a link to the Creative Commons licence, and indicate if changes were made. The images or other third party material in this article are included in the article's Creative Commons licence, unless indicated otherwise in a credit line to the material. If material is not included in the article's Creative Commons licence and your intended use is not permitted by statutory regulation or exceeds the permitted use, you will need to obtain permission directly from the copyright holder. To view a copy of this licence, visit http://creativecommons.org/licenses/by/4.0/.

\section{References}

1. Jacobs DO (2007) Clinical practice. Diverticulitis. N Engl J Med 357(20):2057-2066

2. Peery AF, Barrett PR, Park D, Rogers AJ, Galanko JA, Martin CF, Sandler RS (2012) A high-fiber diet does not protect against asymptomatic diverticulosis. Gastroenterology 142(2):266-272

3. Strate LL, Morris AM (2019) Epidemiology, pathophysiology, and treatment of diverticulitis. Gastroenterology 156(5):1282-1298

4. Wasvary H, Turfah F, Kadro O, Beauregard W (1999) Same hospitalization resection for acute diverticulitis. Am Surg 65(7):632635

5. Francis NK, Sylla P, Abou-Khalil M, Arolfo S, Berler D, Curtis NJ, Dolejs SC, Garfinkle R, Gorter-Stam M, Hashimoto DA, Hassinger TE, Molenaar CJL, Pucher PH, Schuermans V, Arezzo A, Agresta F, Antoniou SA, Arulampalam T, Boutros M, Bouvy N, Campbell K, Francone T, Haggerty SP, Hedrick TL, Stefanidis D, Truitt MS, Kelly J, Ket H, Dunkin BJ, Pietrabissa A (2019) EAES and SAGES 2018 consensus conference on acute diverticulitis management: evidence-based recommendations for clinical practice. Surg Endosc 33(9):2726-2741

6. Regenbogen SE, Hardiman KM, Hendren S, Morris AM (2014) Surgery for diverticulitis in the 21st century: a systematic review. JAMA Surg 149(3):292-303

7. Mizrahi I, Al-Kurd A, Chapchay K, Ag-Rejuan Y, Simanovsky N, Eid A et al (2018) Long-term outcomes of sigmoid diverticulitis: a single-center experience. J Surg Res 221:8-14

8. Frattini J, Longo WE (2006) Diagnosis and treatment of chronic and recurrent diverticulitis. J Clin Gastroenterol 40(Suppl 3):S145S149

9. Moher D, Liberati A, Tetzlaff J, Altman DG, PRISMA Group (2009) Preferred reporting items for systematic reviews and metaanalyses: the PRISMA statement. PLoS Med 21:6(7)

10. Thaler K, Weiss E, Nogueras J, Arnaud JP, Wexner S, Bergamaschi R (2003) Recurrence rates at minimum 5-year follow-up: laparoscopic versus open sigmoid resection for uncomplicated diverticulitis. Surg Laparosc Endosc Percutan Tech 13(5):325-327

11. Lee IK, Lee YS, Kim SJ, Gorden DL, Won DY, Kim HJ, Cho HM, Jeon HM, Kim JG, Oh ST (2010) Laparoscopic and open surgery for right colonic diverticulitis. Am Surg 76(5):486-491

12. Gregersen R, Andresen K, Burcharth J, Pommergaard H-C, Rosenberg J (2018) Long-term mortality and recurrence in patients treated for colonic diverticulitis with abscess formation: a nationwide register-based cohort study. Int J Color Dis 33(4):431-440

13. Benn PL, Wolff BG, Ilstrup DM (1986) Level of anastomosis and recurrent colonic diverticulitis. Am J Surg 151(2):269-271

14. Gervaz P, Mugnier-Konrad B, Morel P, Huber O, Inan I (2011) Laparoscopic versus open sigmoid resection for diverticulitis: long-term results of a prospective, randomized trial. Surg Endosc 25(10):3373-3378

15. Klarenbeek BR, Bergamaschi R, Veenhof AAFA, van der Peet DL, van den Broek WT, de Lange ESM, Bemelman WA, Heres P, Lacy AM, Cuesta MA (2011) Laparoscopic versus open sigmoid resection for diverticular disease: follow-up assessment of the randomized control Sigma trial. Surg Endosc 25(4):1121-1126

16. Letarte F, Hallet J, Drolet S, Charles Grégoire R, Bouchard A, Gagné J-P, Thibault C, Bouchard P (2013) Laparoscopic emergency surgery for diverticular disease that failed medical treatment: a valuable option? Results of a retrospective comparative cohort study. Dis Colon Rectum 56(12):1395-1402

17. Turunen $\mathrm{P}$, Wikström H, Carpelan-Holmström M, Kairaluoma P, Kruuna O, Scheinin T (2010) Smoking increases the incidence of complicated diverticular disease of the sigmoid colon. Scand J Surg 99(1):14-17 
18. Thörn M, Graf W, Stefànsson T, Påhlman L (2002) Clinical and functional results after elective colonic resection in 75 consecutive patients with diverticular disease. Am J Surg 183(1):7-11

19. Bergamaschi R, Arnaud JP (1998) Anastomosis level and specimen length in surgery for uncomplicated diverticulitis of the sigmoid. Surg Endosc 12(9):1149-1151

20. Andeweg C, Peters J, Bleichrodt R, van Goor H (2008) Incidence and risk factors of recurrence after surgery for pathology-proven diverticular disease. World J Surg 32(7):1501-1506

21. Choi KK, Martinolich J, Canete JJ, Valerian BT, Chismark DA, Ata A, Lee EC (2020) Elective Laparoscopic Sigmoid Colectomy for Diverticulitis-an Updated Look at Recurrence After Surgery. J Gastrointest Surg 24(2):388-395

22. Holmer C, Lehmann KS, Engelmann S, Gröne J, Buhr HJ, Ritz J-P (2011) Long-term outcome after conservative and surgical treatment of acute sigmoid diverticulitis. Langenbeck's Arch Surg 396 (6):825-832

23. Regenet N, Pessaux P, Tuech J-J, Hennekinne S, Lermite E, Ridereau-Zins C, Aube C, Bergamaschi R, Jean-Pierre A (2005) Prospective evaluation of the quality of laparoscopic sigmoid resection for diverticular disease. Hepatogastroenterology. 52(65): 1427-1431

24. Thaler K, Baig MK, Berho M, Weiss EG, Nogueras JJ, Arnaud JP, Wexner SD, Bergamaschi R (2003) Determinants of recurrence after sigmoid resection for uncomplicated diverticulitis. Dis Colon Rectum 46(3):385-388

25. Hinchey EJ, Schaal PG, Richards GK (1978) Treatment of perforated diverticular disease of the colon. Adv Surg 12:85-109

26. Hansen O, Graupe F, Stock W (1998) Prognostic factors in perforating diverticulitis of the large intestine. Chir Z Alle Geb Oper Med 69(4):443-449

27. Hupfeld L, Burcharth J, Pommergaard H-C, Rosenberg J (2017) Risk factors for recurrence after acute colonic diverticulitis: a systematic review. Int J Color Dis 32(5):611-622

28. Haas JM, Singh M, Vakil N (2016) Mortality and complications following surgery for diverticulitis: Systematic review and metaanalysis. United European Gastroenterol J 4(5):706-713

Publisher's note Springer Nature remains neutral with regard to jurisdictional claims in published maps and institutional affiliations. 